The application of ethylorthoformate as a photochemical reducing agent in sunlight is still under investigation.

Chemistry Department,

Ahmed Mustafa

Faculty of Science,

Fouad I University,

Abbassia, Cairo.

May 28.

${ }^{1}$ Ber., 33, 2911 (1900).

${ }^{2}$ Cohen, Rec. trav. chim., 39, 243 (1920).

- Comp. Migita, Bull. Chem. Soc. Japan, 7, 334 (1932). Schönberg and Mustafa, J. Chem. Soc., 67 (1944). Bachmann, J. Amer. Chem. Soc., 55,391 (1933).

- Comp. Ciamician and Silber, Ber., 48, 1536 (1910).

${ }^{5}$ Ciamician and Silber, Ber., 44, 1280 (1911). Paterno and Chieffi, Gazz. Chim. Ital., 40, ii, 321 (1910).

- De Fazi, Atti Accad. Lincei, 6, 266 (1925) ; Gazz. Chim. Ital., 57. 551 (1927).

' Comp. Klinger, Ber., 19, 1864 (1886). Ciamician and Silber, Ber.. 34, 1530 (1901).

' Benrath, J. prakt. Chem., 73, 383 (1906).

\section{Fluoranthene Syntheses}

THE recent communication by Bergmann ${ }^{1}$ on the formation of fluoranthene from acenaphthylene and butadiene prompts us to report briefly two somewhat similar syntheses of the hydrocarbon which have been developed in our laboratories.

trans-9: 10-Dimethylacenaphthene-9:10-diol ${ }^{2}$ when heated with acetic anhydride and maleic anhydride readily gives $10: 11: 12: 13$-tetrahydrofluoranthene11 : 12-dicarboxylic acid anhydride (II), presumably by formation of the intermediate 9 : 10-dimethyleneacenaphthene $(\mathrm{I})^{3}$. Dehydrogenation and decarboxylation of the product yield fluoranthene (III).
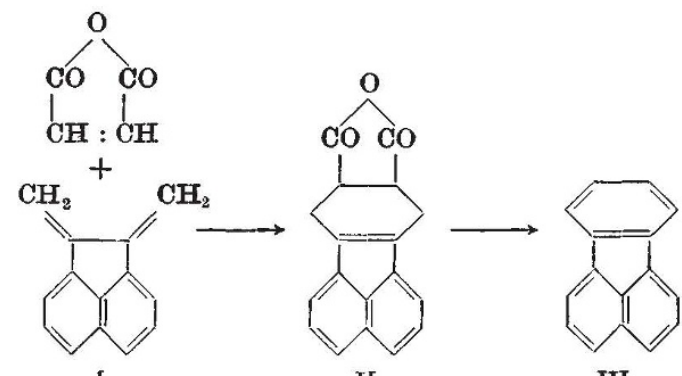

I

II

III

It is obvious that, by the use of substituted acenaphthenes or acenaphthenediols and replacement of the maleic anhydride by other ethylenic components, substituted fluoranthenes of known structure can be obtained. For example, substitution of maleic anhydride by $\alpha$-naphthoquinone in the above reaction gives a quinone, melting point higher than $300^{\circ}$, which must have structure IV. The compound prepared by another method and regarded as having this structure must be the isomeric quinone with formula $V$.
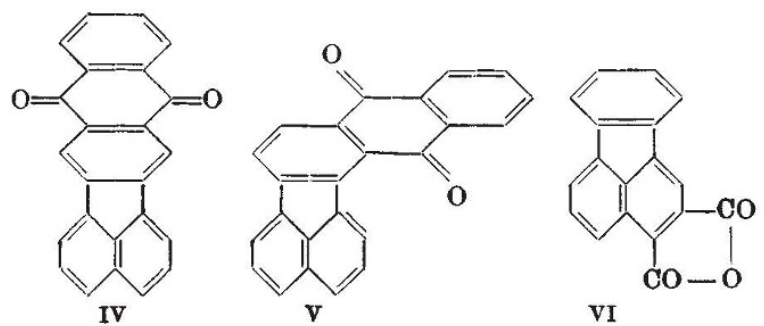

9-Methylfluorenol is known to undergo dehydra. tion to the unstable 9-methylenefluorene ${ }^{5}$. By heating the carbinol with acetic anhydride and maleic anhydride, the intermediate methylene compound gives fluoranthene-3 : 4-dicarboxylic acid anhydride (VI), one of the nuclear double bonds being sufficiently reactive to participate in the Diels - Alder reaction. Decarboxylation gives fluoranthene (III). The reaction does not take place so readily as in the first method, but the structures of the products are unambiguously established.

Details of these and related experiments will $b_{\ni}$ published elsewhere.

Chemistry Department,

University of Edinburgh. June 11.

' Nature, 161, 889 (1948).

${ }^{2}$ Criegee, R., Kraft, L., and Rank, B., Annalen, 507, 159 (1933).

Cf. Maxim, N., Bull. Soc. Chim., 45, 1137 (1929).

-v. Braun and Manz, Annalen, 496, 170 (1932).

'Wieland, Reindel and Ferrer, Ber., 55, 3313 (1922).

\section{Sulphur-containing Steroid Derivatives}

Previous communications ${ }^{1,2}$ have recorded the synthesis of antibacterial compounds derived from bile acids and sterols which contained basic groups, such as the amino-, amidino- and guanido-groups. In general, these derivatives were bacteriostatic for Gram-positive bacteria, but had little activity against Gram-negative organisms. Whereas surface tension measurements seemed to reveal a relationship between the bacteriostatic and surface activities of the bile acids and their anionic derivatives ${ }^{3}$, no such relation. ship was apparent in the properties of a series of the basic steroid compounds ${ }^{4}$. In an extension of these studies, we have synthesized and investigated several water-soluble, sulphur-containing, steroid derivatives.

A series of mercaptals has been obtained by the condensation of thioglycollic acid with various ketoderivatives of steroids, a reaction which occurs with. out a catalyst and appears to be specific for a keto group at position 3 . For example, $3: 7:$ 12-triketo. cholanic acid yielded 3:3-di-(carboxymethylmercapto)-7 : 12-diketocholanic acid, m.p. $203^{\circ},[\alpha] D^{24^{\circ}}$ $+55 \cdot 0^{\circ}$; (trimethyl ester : m.p. $78^{\circ},[\alpha] D^{17.5^{\circ}}+51 \cdot 3^{\circ}$ ); 3-keto-7: 12-dihydroxycholanic acid gave $3: 3$-di(carboxymethylmercapto) - $7:$ 12-dihydroxycholanic acid, m.p. $141^{\circ},[\alpha] D^{20^{\circ}}+35 \cdot 7^{\circ}$; and $\Delta^{4}$-cholesten-3one afforded $3: 3$-di-(carboxymethylmercapto)- $\Delta^{4}$ cholestene, m.p. 122-124,$[\alpha]_{D^{19}}+108^{\circ}$. 3 : 3-Dithiophenyl-7 : 12-diketocholanic acid was derived from the condensation of thiophenol with $3: 7: 12$-triketocholanic acid by a modification of the method of Mylius ${ }^{5}$. In a similar manner, $3: 3$-di(N-acetyl-p. aminothiophenyl)-7: 12-diketocholanic acid: m.p. $165^{\circ},[\alpha] D^{18^{\circ}}+13 \cdot 0^{\circ}$, was obtained by the condensa. tion of $\mathrm{N}$-acetyl-p-aminothiophenol with $3: 7: 12$ triketocholanic acid. The monobasic, sulphurcontaining acid, 3-carboxymethylmercapto- $\Delta^{\mathbf{5}}$-cholestene, m.p. $145^{\circ},[\alpha] D^{21 \circ}-34 \cdot 2^{\circ}$, was obtained by the reaction of thiocholesterol with monochloroacetic acid.

Treatment of the sodio-derivative of thiocholesterol with methyl iodide afforded the methyl thioether, m.p. $141^{\circ},[\alpha] D^{18 \circ}-24 \cdot 6^{\circ}$, which gave, upon further treatment with methyl iodide, $\Delta^{5}$-cholestene-3. 